\title{
REVIEW
}

\section{TSH receptor activation and body composition}

\author{
Anna de Lloyd ${ }^{\mathbf{1} *}$, James Bursell ${ }^{2, *}$, John W Gregory ${ }^{2}$, D Aled Rees ${ }^{\mathbf{1}}$ and Marian Ludgate ${ }^{\mathbf{1}}$ \\ ${ }^{1}$ Centre for Endocrine and Diabetes Sciences and ${ }^{2}$ Department of Child Health, School of Medicine, Cardiff University, Heath Park, Cardiff CF14 4XN, UK \\ (Correspondence should be addressed to M Ludgate; Email: ludgate@cf.ac.uk) \\ *(A de Lloyd and J Bursell contributed equally to this work)
}

\begin{abstract}
The impacts of hyper and hypothyroidism on body composition, i.e. the relative quantity and quality of bone, adipose tissue and muscle, have traditionally been attributed uniquely to abnormal levels of free thyroid hormones. The presence of biologically active TSH receptors in bone, fat and muscle, raises the possibility that both thyroid hormones and
\end{abstract}

TSH contribute to the changes in body composition associated with thyroid disease. This review evaluates the evidence for this in terms of the in vitro experimental approaches applied, data from in vivo sources (i.e. mouse models) and patient-based studies.

Journal of Endocrinology (2010) 204, 13-20

\section{The TSH receptor and its role in the thyroid}

The established biological function of the TSH receptor (TSHR) in the thyroid gland is to regulate synthesis and secretion of thyroid hormones from follicular thyroid cells; it also plays an important role in controlling the growth and development of the thyroid gland (Vassart \& Dumont 1992). The TSHR is a G protein-coupled receptor and shares the classic structure of the serpentine receptor family (i.e. seven membrane spanning segments, three extracellular loops, three intracellular loops, an amino terminal ectodomain and an intracellular carboxy terminal). The hormonal binding specificity of the receptor is determined by the ectodomain (or $\alpha$ subunit; Kleinau \& Krause 2009) whilst coupling to the $G$ protein is via the serpentine portion.

The TSHR is encoded by ten exons located on chromosome 14 and is coupled mainly to the $\alpha$ subunit of the stimulatory guanine-nucleotide-binding protein. In the thyroid, ligand binding predominantly activates adenylate cyclase with a resultant increase in the intracellular concentration of cAMP. Stimulation of the TSHR via this cAMP second messenger system regulates the transcription of genes central to thyroid hormone synthesis. Recent studies have illustrated the potential heterogeneity of signalling via the TSHR either as the consequence of coupling to other $\mathrm{G}$ proteins $\left(G_{\mathrm{q}} / \mathrm{G}_{11}\right.$; Kero et al. 2007) or as a result of cascades stimulated by the liberated $G$ protein $\beta / \gamma$ subunits (Zaballos et al. 2008). Thus, TSHR activation can up-regulate kinases such as phosphoinositide-3 kinase (Zaballos et al. 2008) and
P70S6K (Cass \& Meinkoth 1998) and increase concentrations of the second messengers inositol-phosphate (IP) and diacylglycerol.

Chronic stimulation of the TSHR leads to over activation of the cAMP pathway that in turn causes thyroid hyperplasia and hyperthyroidism. This process occurs in Graves' disease (GD), the commonest cause of hyperthyroidism in which thyroid stimulating antibodies (TSAB) bind the receptor and mimic the action of TSH (Prabhakar et al. 2003). When TSH or TSAB bind to the receptor, they induce a conformational change such that the ectodomain is transformed from a tethered inverse agonist into a full agonist of the receptor's serpentine portion (Vlaeminck-Guillem et al. 2002). This model can also account for a ligand-independent pathogenetic mechanism of receptor activation; gain-of-function mutations. When these are somatic, they cause thyroid toxic adenoma (Parma et al. 1993) but in the germline, they produce familial nonautoimmune hyperthyroidism (Duprez et al. 1994).

More than 30 point mutations that result in increased constitutive activity in the receptor have been described (Paschke \& Ludgate 1997). These mutations are located predominantly in exon 10 , which encodes the serpentine portion of the TSHR. All activating mutations induce an increase in cAMP levels in the absence of TSH but retain TSH responsiveness. The phenotype can vary according to the specific germline mutation but also between individuals harbouring the same point mutation (for example the age of onset of hyperthyroidism). This variation is likely to reflect epigenetic and environmental factors in addition to the 
inherent biological activity of the particular mutant form (e.g. a minority of mutations will increase both cAMP and IP3 concentrations (Fuhrer et al. 2003). Gain-of-function mutations require only one affected allele to induce hyperthyroidism whereas both receptor alleles must be affected for hypothyroidism to occur (homozygous hyt/hyt mouse (Stein et al. 1994)).

A number of families have now been identified that are affected by loss-of-function TSHR mutations (Sunthornthepvarakul et al. 1995). These families have been found to exhibit varying degrees of TSH resistance (as is reflected in the thyroid function test results; extent of the TSH increase and/or thyroid hormone deficiency), which correlates with the clinical phenotype. Individuals with partial resistance to TSH usually retain some TSHR function (Alberti et al. 2002, Jordan et al. 2003), whereas those with complete resistance to TSH do not. TSHR responsiveness ultimately dictates the extent of the hypothyroidism and the degree of thyroid gland hypoplasia incurred.

\section{TSHR expression in tissues other than the thyroid}

In recent years TSHRs have been identified in a number of tissues including brain, testes, kidney, heart, bone, thymus, lymphocytes, adipose tissue and fibroblasts (reviewed in Davies et al. 2002). This suggests that the TSHR may have a wider functional role than is traditionally recognised.

Apart from the earliest studies, which investigated a function for TSH outside the thyroid, much of the recent evidence has been obtained using the PCR. There are several inherent problems with PCR: its sensitivity allows generation of a product even when the target mRNA is present at very low levels (care is therefore required to avoid amplifying from genomic DNA). Also, the presence of a transcript product does not necessarily signify functional protein and finally as PCR is often applied to whole tissues, which are heterogeneous in nature, expression cannot be attributed to a specific cell type. These considerations aside, if the TSHR is expressed at significant levels in tissues outside the thyroid then individuals bearing germline TSHR mutations would be expected to reveal its functional significance; examples will be given in the relevant sub-sections below.

\section{TSHR and adipose tissue}

Adipose tissue is clearly altered in the hypo- or hyperthyroid state. Weight gain occurs in hypothyroidism whereas thyrotoxic patients display weight loss attributed to increased lipolysis consequent to thyroid hormone-induced upregulation of adrenergic receptors (Haluzik et al. 2003). A role for TSH in this process was first suggested by Rodbell (1964) who reported that TSH triggers lipolysis in rat epididymal fat - however this mechanism would decrease fat mass and thus not accord with the typical hypothyroid phenotype.
Winand \& Kohn (1972) described high-affinity TSH binding sites in guinea pig orbital tissue (predominantly fat) leading to a TSH-induced increase in cAMP, which is consistent with its lipolytic action. The application of molecular techniques has confirmed the presence of TSHR in rodent fat, including white and brown adipose tissues (BAT), implicating a role for TSH in regulating thermogenesis (Roselli-Rehfuss et al. 1992). The extensive experiments of Haraguchi et al. $(1996 a, b)$ revealed that the TSHR is expressed (at levels similar to those found in the rat thyroid) during lineagespecific differentiation of preadipocyte precursors into mature fat cells. Very recent studies reported that TSHR deficient hyt/hyt mice became hypothermic in cold conditions despite thyroxine $\left(\mathrm{T}_{4}\right)$ administration. Transfection of TSHR into the BAT of these mice resulted in a marked improvement in core temperature, leading to the conclusion that both a functional TSHR and adequate free thyroid hormones were required for normal temperature regulation (Endo \& Kobayashi 2008).

It is unclear to what extent these findings can be extrapolated to human subjects where BAT makes up 5\% of the body weight of neonates (Lean et al. 1986) and declines further in adults. However, the use of fluorodeoxyglucosepositron emission tomography has revealed several functional BAT deposits in adult humans (Nedergaard et al. 2007). These findings have recently been confirmed using cold-induced glucose uptake in human subjects, which identified BAT depots in the head and neck regions (Virtanen et al. 2009).

As in rodents, the presence of a functioning TSHR in human fat tissue was initially suggested by experiments performed on neonatal adipocytes in which TSH and TSAB were shown to mediate lipolysis in vitro (Marcus et al. 1988, Janson et al. 1995). By a few weeks of age adipocyte sensitivity and responsiveness to TSH declined markedly and catecholamines became the primary mediator of lipolysis (as is the case in adults). In keeping with this finding there is known to be a surge in TSH levels occurring in term infants in the first days of life (a 50-fold physiological rise in TSH levels; Oddie et al. 1978). This is believed to drive lipolysis and generate free fatty acids that serve as the primary energy substrate in the first days of life before breast feeding has become established.

In more recent studies, Crisp et al. (1997) applied northern blot analysis to demonstrate TSHR transcripts in several human adult fat depots including abdominal and orbital sites. This work confirmed earlier PCR based studies, which had indicated increased TSHR expression in orbital fat (Feliciello et al. 1993) from patients with Graves' ophthalmopathy (GO). In this orbital condition, there is expansion of the orbital contents which results in proptosis (Ludgate \& Baker 2002). Subsequent reports from several (but not all) groups revealed that, as in rodents, TSHR expression is upregulated during adipogenesis and the higher level of receptor transcripts in GO orbital fat is the result of this process (Valyasevi et al. 1999, Starkey et al. 2003). However this phenomenon is not unique to orbital fat but occurs in any fat depot undergoing differentiation and is accompanied by increased cAMP in response to TSH activation (Crisp et al. 2000). In contrast to 
rodents, the expression level of TSHR in human adipose tissues is always less than in the thyroid. There have been suggestions that receptor abundance might influence downstream signalling and if true, this could explain the identification of non-cAMP mediated TSH signal transduction (e.g. involving the p70S6 kinase, Bell et al. 2000).

Since TSHR expression is highest during adipogenesis several groups have investigated a role for TSHR activation in the process. The findings of these groups have differed and depended upon the preadipocyte source. Zhang et al. (2006) introduced activating mutant TSHRs into human preadipocytes from normal orbit and GO tissue. TSHR activation stimulated the early stages of adipogenesis but inhibited the terminal stages of differentiation. The absence of lipid-filled droplets despite increased cellular lipid content suggested that either lipolysis had been upregulated, or that the cytoskeletal changes necessary for droplet formation had been inhibited. Lipoprotein lipase transcripts remained at the limit of detection in cells expressing activating mutant TSHR, favouring the latter mechanism. The results agree with earlier reports of cAMP elevation rapidly reducing a suppressor of adipogenesis, Wnt, thereby promoting differentiation (Bennett et al. 2002). In contrast, prolonged elevation of cAMP by pharmacological agents reduced accumulation of lipids in the murine 3T3L1 preadipocyte cell line, by decreasing key lipogenic enzymes rather than increasing lipolysis (Spiegelman \& Green 1981). Studies performed in our laboratory demonstrated that Gs $\alpha$ signalling (increases cAMP) impedes FOXO1 phosphorylation and inhibits $P P A R G$ transcription and the alternative promoter usage required to generate PPARG2, the fat-specific transcription factor necessary for adipogenesis (Zhang et al. 2009). However, in mouse embryonic stem cells TSH stimulated adipogenesis ( $\mathrm{Lu} \& \mathrm{Lin} 2008$ ).

Orbital fat is distinct from other adipose tissue and has been found to have features in common with BAT. This is exemplified by mice that overexpress adiponectin, which resulted in expansion of both the orbital and the intra-scapular brown-fat pad (Combs et al. 2004). There have been reports of infants with activating TSHR mutations being born with proptosis (De Roux et al. 1996). Although controversial, this may be the result of increased orbital adipogenesis occurring as a consequence of the activating receptor mutation (a similar phenomenon to that occurring in GO; Sorisky et al. 1996). However, in the absence of appropriate magnetic resonance imaging scans to confirm fat expansion in these children, this remains a hypothesis.

Preadipocytes resemble fibroblasts and are mesenchymal stem cells (MSC) that are present in fat tissue and its stroma. MSC are able to differentiate along several distinct lineages including adipocyte, osteoblast, chondrocyte and myocyte, all of which are central contributors to body composition (Schaffler \& Buchler 2007). The differences in the impact on adipogenesis observed between embryonic stem cells and the murine cell line suggest a role for TSHR activation in lineage commitment, rather than terminal differentiation perse (Fig. 1).

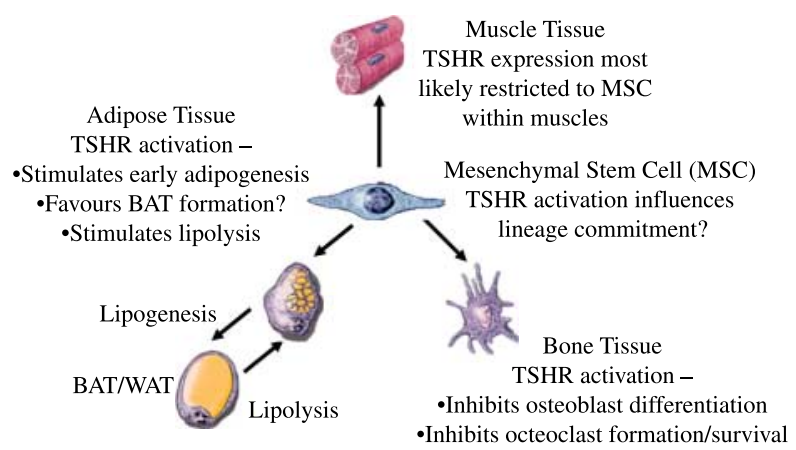

Figure 1 Tissue-specific actions of TSHR activation: potential sites impacting on body composition.

Most receptor activation is due to circulating TSH, whose levels decrease following food restriction, although this can be prevented by leptin administration (Seoane et al. 2000), implying a role for adipose tissue itself in regulating the hypothalamic/pituitary/thyroid axis (Bluher \& Mantzoros 2004). Although the effects are clear cut in rodent studies, the situation in humans is far from clear with contrasting results being reported even when seeking an association between serum TSH and body mass index (BMI; Manji et al. 2006, Nymes et al. 2006).

\section{TSHR and muscle}

Thyroid disease is known to affect muscle function. Hyperthyroidism can lead to skeletal muscle weakness, wasting, cardiac myopathy and heart failure. The extra-ocular muscles are affected in GD where inflammation causes hypertrophy and eventually fibrosis, which may result in restricted motility. Hypothyroid patients also suffer muscular involvement including myalgia, weakness and exercise intolerance. It is thus appropriate to investigate whether the TSHR plays a role in the pathogenesis of these muscle disorders.

The presence of TSHR in the extraocular muscles of GD patients has been established using high-stringency PCR and in situ hybridisation techniques (Busuttil \& Frauman 2001), which failed to detect TSHR mRNA in either the abdominal or cardiac muscle of these patients. These results differ in their findings from other studies using immunohistochemistry that failed to demonstrate TSHR expression in the extraocular muscles of GO patients (Spitzweg et al. 1997). In general, the evidence for TSHR in extraocular muscle is less abundant than the data demonstrating TSHR in adipose tissue. The selective expression of TSHR in extraocular muscle reported by Kloprogge et al. (2005) contrasts with the more widespread nature of TSHR expression in various GD fat depots (Starkey et al. 2003). The extraocular muscle enlargement in GO has previously been considered to be the result of inflammation and oedema rather than hyperplasia or hypertrophy of the myocytes themselves (Hufnagel et al. 1987). 
Contradictory results have also been reported for the presence of the TSHR in cardiomyocytes. Drvota et al. (1995) used northern blots and in vitro cultures to demonstrate a functional TSHR in heart muscle. However, these conclusions were refuted by Busuttil \& Frauman (2001) who suggested 'that certain confounding positive tissues, rather than myocardial tissue itself, may have contributed to the positive results'. This suggestion certainly fits with the report of Spitzweg et al. (1997) who applied immunohistochemistry to show that the TSHR was expressed on perimysial fibroblasts within extraocular muscle, but not in extraocular muscle fibres themselves. Boschi et al. (2005) obtained similar results, concluding that in GO orbits TSHR was expressed on the fibroblast-like cells positioned between myocytes, but not on the myocytes.

Taken together it is likely that the expression of TSHR in muscles from various locations is due to fibroblast-like cells existing within the muscles, which are likely to represent MSC. Co-localisation experiments using antibodies to MSC surface markers (e.g. CD34, Sca1 and the TSHR) are required to confirm or refute this hypothesis.

\section{TSHR and bone}

Mammalian skeletal remodelling occurs as old bone is resorbed by the action of osteoclasts and is replaced by new bone deposited by osteoblasts. Any disturbance or uncoupling in the equilibrium between these two dynamic processes will lead to either excessive and disordered bone formation or a higher rate of uncompensated bone loss. Thyroid disease is known to affect this balance; hyperthyroidism is associated with a reduction in bone mass and osteoporosis (Greenspan \& Greenspan 1999) and even a history of previous hyperthyroidism increases the risk of bone fracture (Allain \& McGregor 1993). There is some evidence that subclinical hyperthyroidism reduces bone mineral density (BMD) but this is not a universal finding; an increased fracture risk has been suggested in women over the age of 65 years who have a TSH below $0 \cdot 1 \mathrm{mU} / 1$ (Biondi et al. 2005). Poorly controlled hypothyroidism also affects bone health where in childhood it is associated with delayed bone age and growth arrest (Rivkees et al. 1988).

The mechanisms by which thyroid dysfunction mediates these effects on bone growth are yet to be fully elucidated. It had previously been considered that the thyroid hormones tri-iodothyronine $\left(T_{3}\right)$ and $T_{4}$ were the principal mediators of bone remodelling. However, recent evidence has suggested that rather than thyroid bone disease being solely due to the effects of $T_{3}$ and $T_{4}$, the concomitantly low or elevated TSH may play an important role in bone metabolism and homeostasis (Williams 2009). This postulate is supported by data from mice lacking $\alpha_{1}$ and $\beta_{1}$ thyroid hormone receptors, which were found to have skeletal morphogenesis and growth plate abnormalities but no uncoupling of osteoclast and osteoblast action and thus normal bone density (Gothe et al. 1999).
Evidence for the presence of the TSHR in a rat osteosarcoma cell line (UMR106) was provided by Inoue et al. (1998), using northern blot analysis and TSH binding. Tsai et al. (2004), applied several transcript detection and biochemical techniques to provide evidence of functional TSHRs in human osteoblast-like (hOB) cells. Morimura et al. (2005) studied the expression of functional TSHR and type 2 iodothyronine deiodinase (D2) in human osteoblasts (NHOst) and osteosarcoma (SaOS-2) cell lines. D2 (which converts $\mathrm{T}_{4}$ to the biologically active $T_{3}$ ) is regulated in human thyroid and rat BAT by TSHR mediated cAMP increase (Murakami et al. 2001a,b). Levels of D2 expression and activity in both cell lines were increased following incubation with cAMP mimetics or $\mathrm{TSH}$, suggesting that $\mathrm{D} 2$ expression in NHOst and SaOS-2 cells is also regulated by the TSH-receptor/cAMP pathway (TSHR mRNA was demonstrated in the cell lines by PCR). Thus, it seems that TSH may influence bone remodelling directly, as well as indirectly through its effect on D2 and the $\mathrm{T}_{3}$ levels.

The argument for a direct role of TSH in bone metabolism and skeletal remodelling was strengthened by experiments performed on mice homozygous and heterozygous for an exon deletion in the TSHR gene (Abe et al. 2003). TSHR $-/-$ mice were hypothyroid with low serum $\mathrm{T}_{3}$ and $\mathrm{T}_{4}$ levels and elevated TSH. They died prematurely and displayed poor growth, reduced femur length and osteoporosis with reduced BMD. Thyroid hormone supplementation improved body weight but not bone mass, bone length or BMD. Heterozygote $+/-$ mice, which had normal $\mathrm{T}_{3}, \mathrm{~T}_{4}$ and TSH levels, grew and reproduced normally although with a significantly reduced BMD. In heterozygotes and homozygous TSHR $-/-$ mice, the reduced $\mathrm{BMD}$ was the consequence of increased bone turnover. Ex vivo bone marrow cultures showed a two-fold increase in osteoclast formation in cells from TSHR $+/-$ and $-/-$ mice as well as evidence of upregulated osteoblast differentiation. Experiments demonstrating TSH inhibition of osteoclast formation and survival, as well as independent inhibition of osteoblast differentiation, further demonstrated a possible role of TSH in bone metabolism and were consistent with TSHR expression being maximal during the early and mid phases of osteoblast and osteoclast formation.

This work of Abe et al. provides strong evidence for a fundamental role for TSHR in skeletal modelling. A 50\% reduction in TSHR expression produced osteoporosis and focal vertebral body osteosclerosis despite normal thyroid function. This group argue that their data support the hypothesis that bone disease associated with thyroid dysfunction may be due to altered TSH levels rather than changes in serum thyroid hormone levels per se (Sun et al. 2006). Interestingly, our own unit has reported brothers with congenital hypothyroidism, homozygous for W546X (Jordan et al. 2003; i.e. the human equivalent of the TSHR - /mice). One of the boys has developed a benign osteoblastoma on his radius, and we speculate that this mirrors the focal sclerosis seen in the TSHR - / - mice (M Ludgate \& J W Gregory, unpublished observation). 
Other authors (Galliford et al. 2005) however have suggested that the reduction in BMD in TSHR heterozygote $+/-$ and homozygous $-/-$ mice despite thyroid hormone supplementation may not reflect a role of TSHR but rather a delay in ossification and growth impairment secondary to antenatal hypothyroidism (or the period of hypothyroidism prior to receiving thyroid replacement at 3 weeks of age). This period of foetal hypothyroidism in TSHR $-/-$ mice may have resulted in an increased sensitivity to thyroid hormone as is described in mice with complete deficiency of thyroid hormone receptor that were then given thyroid replacement (Macchia et al. 2001). Thus, the changes noted following supplementation at weaning might reflect a disproportionately large response to $T_{3}$ and $T_{4}$ rather then effects of TSHR deficiency.

Subsequent studies have also cast doubt upon the putative role of the TSHR in bone metabolism. Studies using hyt/hyt mice (elevated TSH and inactive TSHRs) that have a point mutation in the Tshr gene and Pax $8-/-$ mice (grossly elevated TSH levels with normal TSHR function and thyroid agenesis) suggest that the skeletal phenotype of both sets of hypothyroid mice was independent of TSH levels (Bassett et al. 2008). Both groups of mice demonstrated a significant reduction in bone length and micro-mineralisation and a significant increase in growth plate total width, reserve and proliferative zones.

Using mice that lacked thyroid receptor $\operatorname{TR} \alpha$ or $\operatorname{TR} \beta$ isoforms, Bassett et al. (2007), demonstrated that bone loss in thyrotoxic mice was a result of raised circulating free $T_{3}$ levels and independent of circulating TSH concentrations. Adult TR $\alpha$ null mice had osteosclerosis despite normal levels of TSH and thyroid hormones, whereas $\operatorname{TR} \beta$ null mice had osteoporosis despite elevated TSH and thyroid hormones. The authors postulated that the changes in bone morphology were mediated principally by the thyroid hormone receptor.

Murphy et al. (2006) investigated the effects of TSH and monoclonal TSAB on mouse and hOBs and osteoclasts. Treatment with TSH or TSAB failed to produce evidence of TSHR activated intracellular signalling as measured by cAMP levels. These authors also used recombinant thyrostimulin, a hormone having high affinity for the TSHR (the product of genes for $\alpha-2$ and $\beta-5$ glycoprotein hormone subunits, Nakabayashi et al. 2002), again without effect. These data question whether the TSHR is involved in bone remodelling and, if it is implicated, the signalling pathway in operation in the absence of a cAMP response.

The role of TSH and the TSHR in bone metabolism however is strengthened by data from human subjects with a TSHR Asp727Glu polymorphism. In vitro studies demonstrate an increased cAMP response to TSH but in vivo expression of this polymorphism is associated with reduced circulating TSH levels despite $\mathrm{T}_{4}$ and $\mathrm{T}_{3}$ within the normal range. Individuals heterozygous for TSHR Asp727Glu were found to have increased femoral neck BMD and bone mineral content (Van Der Deure et al. 2008). These data suggest that the polymorphism is associated with a relative TSHR gain-of-function, which has itself affected bone turnover.

Recent work by Sampath et al. (2007) in ovariectomised rats demonstrated that TSH administration increased BMD, trabecular bone volume, trabecular thickness, cortical thickness and enhanced mechanical strength, compared to controls. These changes were mediated by inhibition of osteoclast differentiation and also by activation of osteoblast differentiation. In an extension of this work, Sun et al. (2008) reported that TSH therapy administered as infrequently as once per fortnight displays powerful anti-resorptive action in the bones of ovariectomised rodents.

\section{Effects of TSHR dysfunction on body composition}

The potential wider systemic effect of TSHR dysfunction upon body composition rather than just focal bone or adipose changes has been raised by the findings of Vaidya et al. (2004). They assessed the prevalence of premature birth and low birth weight in families with non-autoimmune hypothyroidism and hyperthyroidism secondary to loss-of-function and gainof-function TSHR mutations respectively. They found that individuals with activating mutations were more likely to be born prematurely $(80 \%$ compared to $6 \%$ of children with inactivating TSHR mutations) and that they were significantly smaller (2338 $\mathrm{g}$ compared with $3470 \mathrm{~g}(P=0 \cdot 004))$. This finding of lower birth weights was not considered to be explained solely by the earlier gestation as they were also smaller as determined by centiles for birth weight $(28 \cdot 4 \%$ compared with $49 \cdot 1 \%$ ). However, any effect of possible foetal thyrotoxicosis upon premature delivery and foetal birth weight was not determined in this study.

As mentioned earlier, serum TSH levels have been shown to be positively associated with BMI (Nyrnes et al. 2006). However, this was not the finding of others including Peeters et al. (2007); who had assessed a population of euthyroid elderly men. Instead, they reported an association between TSH levels and serum leptin levels within this cohort. This finding again contrasts with the work of Miyakawa et al. (1999), who found that free $\mathrm{T}_{4}$ and $\mathrm{TSH}$ did not correlate with serum leptin levels in patients with thyroid disease (GD and Hashimoto's thyroiditis). Percentage fat mass assessed by bioelectrical impedance was lower in GD patients and higher in hypothyroid patients compared with controls thus reiterating the changes in body composition that are associated with thyroid disease. However, percentage fat mass was not directly related to thyroid hormone or TSH levels.

The hypothesis that activation of the TSHR affects body composition would predict that individuals with germline mutations in the TSHR might demonstrate differences in parameters of body composition such as height, weight, BMI, BMD and body fat. Baker et al. (2004) have reported detailed body composition data using dual energy X-ray 
absorptiometry and skin fold measurements in three individuals rendered biochemically euthyroid after treatment for hyperthyroidism, which had been caused by three different gain-of-function mutations. The data demonstrated reduced body fat content in these three children compared with that seen in other unaffected family members. Unfortunately a number of potential confounding factors may have contributed to the changes in BMI and body composition observed in these cases (i.e. nutritional, social and psychological factors, changes associated with age group and the wide variance seen within the normal population) therefore deciphering the contribution made by altered TSHR activity per se is very difficult. Much larger observational studies are required to draw more meaningful conclusions; however, these data lend support to the hypothesis that changes in TSHR activity may influence adipose tissue, muscle and bone sufficiently to affect body composition.

\section{Conclusions}

The role of the TSHR in controlling thyroid function is well established and more recent data have confirmed the presence of the TSHR in tissues relevant to body composition. Furthermore, modifications in TSHR activity have been demonstrated to be associated with changes in bone and adipose tissue metabolism (at all stages from neonate to old age) in agreement with the well-characterised phenotype that is the consequence of thyroid dysfunction. The inverse relationship that exists between adipogenesis and osteogenesis is supported by the association of fatty bone marrow and low BMD (Meunier et al. 1971). This suggests that TSHR activation may play a role in determining MSC lineage commitment and therefore influence body composition directly and independently of thyroid hormone level. The signalling cascades responsible may be distinct from the cAMP pathway that predominates in the thyroid. This merits further investigation as thyroid dysfunction is common and affected individuals may be at risk of complications as a consequence of TSAB in GD or altered TSH in subclinical or clinical thyroid disease.

\section{Declaration of interest}

The authors report that there is no conflict of interest that could be perceived as prejudicing the impartiality of the research reported.

\section{Funding}

This research did not receive any specific grant from any funding agency in the public, commercial or not-for-profit sector.

\section{Reference}

Abe E, Marians RC, Yu W, Wu XB, Ando T, Li Y, Iqbal J, Eldiery L, Rajendren G \& Blair HC 2003 TSH is a negative regulator of skeletal remodelling. Cell 115 151-162.
Alberti L, Proverbio MC, Costagliola S, Romoli R, Boldrighini B, Vigone MC, Weber G, Chiumello G, Beck-Peccoz P \& Persani L 2002 Germline mutation of the TSH receptor gene as cause of nonautoimmune subclinical hypothyroidism. Journal of Clinical Endocrinology and Metabolism 87 2549-2555.

Allain TJ \& McGregor AM 1993 Thyroid hormones and bone. Journal of Endocrinology 139 9-18.

Baker GR, Gregory JW, Bakhsh A, Betts PR, Hughes IA \& Ludgate M 2004 Biological consequences of gain-of-function TSHR mutant expression in adipose tissue. Endocrine Abstracts 7 OC18.

Bassett JHD, O'Shea PJ, Sriskantharajah S, Rabier B, Boyde A, Howell PGT, Weiss RE, Roux JP, Malaval L \& Clement-Lacroix P 2007 Thyroid hormone excess rather than thyrotropin deficiency induces osteoporosis in hyperthyroidism. Molecular Endocrinology 21 1095-1107.

Bassett JHD, Williams AJ, Murphy E, Boyde A, Howell PGT, Swinhoe R, Archanco M, Flamant F, Samarut J \& Costagliola S 2008 A lack of thyroid hormones rather than excess thyrotropin causes abnormal skeletal development in hypothyroidism. Molecular Endocrinology 22 501-512.

Bell A, Gagnon A, Grunder L, Parikh SJ, Smith TJ \& Sorisky A 2000 Functional TSH receptor in human abdominal preadipocytes and orbital fibroblasts. American Journal of Physiology. Cell Physiology 279 C335-C340.

Bennett CN, Ross SE, Longo KA, Bajnok L, Hemati N, Johnson KW, Harrison SD \& MaxDougald OA 2002 Regulation of Wnt signaling during adipogenesis. Journal of Biological Chemistry 277 30998-31004.

Biondi B, Palmieri EA, Klain M, Schlumberger M, Filetti S \& Lombardi G 2005 Subclinical hyperthyroidism: clinical features and treatment options. European Journal of Endocrinology 152 1-9.

Bluher S \& Mantzoros CS 2004 The role of leptin in regulating neuroendocrine function in humans. Journal of Nutrition $1342469 \mathrm{~s}-2474 \mathrm{~s}$.

Boschi A, Daumerie C, Spiritus M, Beguin C, Senou M, Yuksel D, Duplicy M, Costagliola S, Ludgate M \& Many M 2005 Quantification of cells expressing the thyrotropin receptor in extraocular muscles in thyroid associated orbitopathy. British Journal of Ophthalmology 89 724-729.

Busuttil B \& Frauman A 2001 Extrathyroidal manifestations of Graves' disease: the thyrotropin receptor is expressed in extraocular, but not cardiac, muscle tissues. Journal of Clinical Endocrinology and Metabolism 86 2315-2319.

Cass LA \& Meinkoth JL 1998 Differential effects of cyclic adenosine $3^{\prime}, 5^{\prime}$ monophosphate on p70 ribosomal S6 kinase. Endocrinology 139 1991-1998.

Combs TP, Pajvani UB, Berg AH, Lin Y, Jelicks LA, Laplante M, Nawrocki AR, Rajala MW, Parlow AF \& Cheeseboro L 2004 A transgenic mouse with a deletion in the collagenous domain of adiponectin displays elevated circulating adiponectin and improved insulin sensitivity. Endocrinology 145 367-383.

Crisp M, Lane C, Halliwell M, Wynford-Thomas D \& Ludgate M 1997 Thyrotropin receptor transcripts in human adipose tissue. Journal of Clinical Endocrinology and Metabolism 82 2003-2005.

Crisp M, Starkey KJ, Lane C, Ham J \& Ludgate M 2000 Adipogenesis in thyroid eye disease. Investigative Ophthalmology \& Visual Science $\mathbf{4 1}$ 3249-3255.

Davies T, Marians R \& Latif R 2002 The TSH receptor reveals itself. Journal of Clinical Investigation 110 161-164.

Van Der Deure WM, Uitterlinden AG, Hofman A, Rivadeneira F, Pols HA, Peters RP \& Visser TJ 2008 Effects of serum TSH and $\mathrm{fT}_{4}$ levels and the TSHR-Asp727Glu polymorphism on bone: the Rotterdam study. Clinical Endocrinology 68 175-181.

Drvota V, Janson A, Norman C, Sylvén C, Häggblad J, Brönnegård M \& Marcus C 1995 Evidence for the presence of functional thryotropin receptor in cardiac muscle. Biochemical and Biophysical Research Communications 211 426-431.

Duprez L, Parma J, Van Sande J, Allgeier A, Leclère J, Schvartz C, Delisle MJ, Decoulx M, Orgiazzi J \& Dumont J 1994 Germline mutations in the thyrotropin receptor gene cause non-autoimmune autosomal dominant hyperthyroidism. Nature Genetics 7 396-401.

Endo T \& Kobayashi T 2008 Thyroid-stimulating hormone receptor in brown adipose tissue is involved in the regulation of thermogenesis. American Journal of Physiology. Endocrinology and Metabolism 295 E514-E518. 
Feliciello A, Porcellini A, Ciullo I, Bonavolontà G, Avvedimento EV \& Fenzi G 1993 Expression of thyrotropin-receptor mRNA in healthy and Graves' disease retro-orbital tissue. Lancet 342 337-338.

Field JB, Ealey PA, Marshall NJ \& Cockcroft S 1987 Thyroid-stimulating hormone stimulates increases in inositol phosphates as well as cyclic AMP in the FRTL-5 rat thyroid cell line. Biochemical Journal 247 519-524.

Fuhrer D, Lewis MD, Alkhafaji F, Starkey K, Paschke R, Wynford-Thomas D, Eggo M \& Ludgate M 2003 Biological activity of activating thyroidstimulating hormone receptor mutants depends on the cellular context. Endocrinology 144 4018-4030.

Galliford TM, Murphy E, Williams AJ, Bassett JHD \& Williams GR 2005 Effects of thyroid status on bone metabolism: a primary role for thyroid stimulating hormone or thyroid hormone. Minerva Endocrinologica 30 237-246.

Gothe S, Wang Z, Ng L, Kindblomm J, Barrosm A, Ohlssonm C, Vennstrom B \& Forrest D 1999 Mice devoid of all known thyroid hormone receptors are viable but exhibit disorders of the pituitary-thyroid axis, growth and bone maturation. Genes and Development 13 1329-1341.

Greenspan SL \& Greenspan FS 1999 The effect of thyroid hormone on skeletal integrity. Annals of Internal Medicine 130 750-758.

Haluzik M, Nedvidkova J, Bartak V, Dostalova I, Vlcek P, Racek P, Taus M, Svacina S, Alesci S \& Pacak K 2003 Effects of hypo- and hyperthyroidism on noradrenergic activity and glycerol concentrations in human subcutaneous abdominal adipose tissue assessed with microdialysis. Journal of Clinical Endocrinology and Metabolism 88 5605-5608.

Haraguchi K, Shimura H, Lin L, Saito T, Endo T \& Onaya T $1996 a$ Differentiation of rat preadipocytes is accompanied by expression of thyrotropin receptors. Endocrinology 137 3200-3205.

Haraguchi K, Shimura H, Lin L, Saito T, Endo T \& Onaya T 1996 b Functional expression of thyrotropin receptor in differentiated 3T3-L1 cells: a possible model cell line of extrathyroidal expression of thyrotropin receptor. Biochemical and Biophysical Research Communications 223 193-198.

Hufnagel T, Hickey W, Cobbs W, Jacobiec F, Iwamoto T \& Eagle R 1987 Immunohistochemical and ultrastructural studies on the exenterated orbital tissues of a patient with Graves' disease. Ophthalmology 91 1411-1419.

Inoue M, Tawata M, Yokomori N, Endo T \& Onaya T 1998 Expression of thryotropin receptor on clonal osteoblast-like rat osteosarcoma cells. Thyroid 8 1059-1064.

Janson A, Karlsson FA, Michajohansson G, Bolme P, Bronnedard M \& Marcus C 1995 Effects of stimulatory and inhibitory thyrotropin receptor antibodies on lipolysis in infant adipocytes. Journal of Clinical Endocrinology and Metabolism 80 1712-1716.

Jordan N, Williams N, Gregory JW, Evans C, Owen M \& Ludgate M 2003 The W546X mutation of the thyrotropin receptor gene: potential major contribution to thyroid dysfunction in a caucasian population. Journal of Clinical Endocrinology and Metabolism 88 1002-1005.

Kero J, Ahmed K, Wettschureck N, Tunaru S, Wintermantel T, Greiner E, Schütz G \& Offermanns S 2007 Thyrocyte-specific $\mathrm{G}_{\mathrm{q}} / \mathrm{G}_{11}$ deficiency impairs thyroid function and prevents goiter development. Journal of Clinical Investigation 117 2399-2407.

Kleinau G \& Krause G 2009 Thyrotropin and homologous glycoprotein hormone receptors: structural and functional aspects of extracellular signaling mechanisms. Endocrine Reviews 30 133-151.

Kloprogge S, Busuttil B \& Frauman AG 2005 TSH receptor protein is selectively expressed in normal human extraocular muscle. Muscle \& Nerve 32 95-98.

Lean ME, James WP, Jennings G \& Trayhurn P 1986 Brown adipose tissue uncoupling protein content in human infants, children and adults. Clinical Science 71 291-297.

Lu M \& Lin RY 2008 TSH stimulates adipogenesis in mouse embryonic stem cells. Journal of Endocrinology 196 159-169.

Ludgate M \& Baker G 2002 Unlocking the immunological mechanisms of orbital inflammation in thyroid eye disease. Clinical and Experimental Immunology 127 193-198.

Macchia PF, Takeuchi Y, Kawai T, Cua K, Gauthier K \& Chassande O 2001 Increased sensitivity to thyroid hormone in mice with complete deficiency of thyroid hormone receptor alpha. PNAS 98 349-354.
Marcus C, Erhen H, Bolme P \& Armer P 1988 Regulation of lipolysis during the neonatal period importance of thyrotropin. Journal of Clinical Investigation 82 1793-1797.

Manji N, Boelaert K, Sheppard MC, Holder RL, Gough SC \& Franklyn JA 2006 Lack of association between serum TSH or free $\mathrm{T}_{4}$ and body mass index in euthyroid subjects. Clinical Endocrinology 64 125-128.

Meunier P, Aaron J, Edouard C \& Vignon G 1971 Osteoporosis and the replacement of cell populations of the marrow by adipose tissue. A quantitative study of 84 iliac bone biopsies. Clinical Orthopaedics and Related Research 80 147-154.

Miyakawa M, Tsushima T, Murakami H, Isozaki O \& Takano K 1999 Serum leptin levels and bioelectrical impedance assessment of body composition in patients with Graves' disease and hypothyroidism. Endocrine Journal 46 665-673.

Morimura T, Tsunekawa K, Kasahara T, Seki K, Ogiwara T, Mori M \& Murakami M 2005 Expression of type 2 iodothyronine deiodinase in human osteoblast is stimulated by thytotropin. Endocrinology $\mathbf{1 4 6}$ 2077-2084.

Murakami M, Hosoi Y, Negishi T, Kamiya Y, Miyashita K, Yamada M, Iriuchijima T, Yokoo H, Yoshida I \& Tsushima Y 1996 Thymic hyperplasia in patients with Graves' disease. Identification of thyrotropin receptors in human thymus. Journal of Clinical Investigation 98 2228-2234.

Murakami M, Araki O, Hosoi Y, Kamiya Y, Morimura T, Ogiwara T, Mizuma H \& Mori M 2001a Expression and regulation of type II iodothyronine deiodinase in human thyroid gland. Endocrinology 142 2961-2967.

Murakami M, Kamiya Y, Morimura T, Araki O, Imamura M, Ogiwara T, Mizuma H \& Mori M $2001 b$ Thyrotropin receptors in brown adipose tissue: thyrotropin stimulates type II iodothyronine deiodinase and uncoupling protein-1 in brown adipocytes. Endocrinology 142 1195-1201.

Murphy E, Williams AJ, Galliford TM, Costagliola S, Vassart G, Bassett JHD \& Williams GR 2006 TSH receptors action in osteoblasts and osteoclasts in vitro. Endocrine Abstracts 11 OC51.

Nakabayashi K, Matsumi H, Bhalla A, Bae J, Mosselman S, Hsu SY \& Hsueh AJW 2002 Thyrostimulin, a heterodimer of two new human glycoprotein hormone subunits, activates the thyroid-stimulating hormone receptor. Journal of Clinical Investigation 109 1445-1452.

Nedergaard J, Bengtsson T \& Cannon B 2007 Unexpected evidence for active brown adipose tissue in adult humans. American Journal of Physiology. Endocrinology and Metabolism 293 E444-E452.

Nyrnes A, Jorde R \& Sundfjord J 2006 Serum TSH is positively associated with BMI. International Journal of Obesity 30 100-105.

Oddie TH, Bernard B, Presley M, Klein AH \& Fisher DA 1978 Damped oscillations in serum thyroid hormone levels of normal newborn infants. Journal of Clinical Endocrinology and Metabolism 47 61-65.

Parma J, Duprez L, Vansande J, Cochaux P, Gervy C, Mockel J, Dumont J \& Vassart G 1993 Somatic mutations in the thyrotropin receptor gene cause hyperfunctioning thyroid adenomas. Nature 365 649-651.

Paschke R \& Ludgate M 1997 The thyrotropin receptor in thyroid disease. New England Journal of Medicine 337 1675-1681.

Peeters RP, Van Der Deure WM, Van Der Beld AW, Van Toor H, Lamberts SWJ, Janssen JA, Uitterlinden AG \& Visser TJ 2007 The Asp727Glu polymorphism in the TSH receptor is associated with insulin resistance in healthy elderly men. Clinical Endocrinology 66 808-815.

Prabhakar BS, Bahn RS \& Smith TJ 2003 Current perspective on the pathogenesis of Graves' disease and ophthalmopathy. Endocrine Reviews 24 802-835.

Rivkees SA, Bode HH \& Crawford JD 1988 Long-term growth in juvenile acquired hypothyroidism: the failure to achieve normal adult stature. New England Journal of Medicine 318 599-602.

Rodbell M 1964 Metabolism of isolated fat cells. Effects of hormones on glucose metabolism and lipolysis. Journal of Biological Chemistry 239 375-380.

Roselli-Rehfuss L, Robbins LS \& Cone RD 1992 Thyrotropin receptor messenger ribonucleic acid is expressed in most brown and white adipose tissues in the guinea pig. Endocrinology 130 1857-1861. 
De Roux N, Polak M, Couet J, Leger J, Czernichow P, Milgrom E \& Misrahi M 1996 A neomutation of the thyroid stimulating hormone receptor in a severe neonatal hyperthyroidism. Journal of Clinical Endocrinology and Metabolism 81 2023-2026.

Sampath TK, Simic P, Sendak R, Draca N, Bowe AE, O'Brien S, Schiavi SC, McPherson JM \& Vukicevic S 2007 TSH restores bone volume, microarchitecture and strength in ovareictomized rats. Journal of Bone and Mineral Research 22 849-859.

Schaffler A \& Buchler C 2007 Concise review: adipose tissue-derived stromal cells - basic and clinical implications for novel cell-based therapies. Stem Cells 25 818-827.

Seoane LM, Carro E, Tovar S, Casanueva FF \& Dieguez C 2000 Regulation of in vivo TSH secretion by leptin. Regulatory Peptides 92 25-29.

Sorisky A, Pardasani D, Gagnon A \& Smith TJ 1996 Evidence of adipocyte differentiation in human orbital fibroblasts in primary culture. Journal of Clinical Endocrinology and Metabolism 81 3428-3431.

Spiegelman B \& Green H 1981 Cyclic AMP-mediated control of lipogenic enzyme synthesis during adipose differentiation of 3T3 cells. Cell $\mathbf{2 4}$ 503-510.

Spitzweg C, Joba W, Hunt N \& Heufelder A 1997 Analysis of human thyrotropin receptor gene expression and immunoreactivity in human orbital tissue. European Journal of Endocrinology 136 599-607.

Starkey K, Janezic A, Jones G, Jordan N, Baker G \& Ludgate M 2003 Adipose thyrotropin receptor expression is elevated in Graves' and thyroid eye diseases ex vivo and indicates adipogenesis in progress in vivo. Journal of Molecular Endocrinology 30 369-380.

Stein SA, Oates EL \& Hall CR 1994 Identification of a point mutation in the thyrotropin receptor of the hyt/hyt hypothyroid mouse. Molecular Endocrinology 8 129-138.

Sun L, Davies TF, Blair HC, Abe E \& Zaidi M 2006 TSH and bone loss. Annals of the New York Academy of Sciences 1068 309-318.

Sun L, Vukicevic S, Baliram R, Yang G, Sendak R, McPherson J, Ling-Lang Z, Iqbal J, Latif R \& Zaidi M 2008 Intermittent recombinant TSH injections prevent ovariectomy-induced bone loss. PNAS 105 4289-4294.

Sunthornthepvarakul T, Gottschalk ME, Hayashi Y \& Refetoff S 1995 Resistance to thyrotropin caused by mutations in the thyrotropin-receptor gene. New England Journal of Medicine 332 155-160.

Tsai JA, Janson A, Bucht E, Kindmark H, Marcus C, Stark A, Rawet Zemack H \& Torring O 2004 Weak evidence of thyrotropin receptors in primary cultures of human osteoblast-like cells. Calcified Tissue International 74 386-491.
Vaidya B, Campbell V, Tripp JH, Spyer G, Hattersley AT \& Ellard S 2004 Premature birth and low birth weight associated with nonautoimmune hyperthyroidism due to an activating thyrotropin receptor gene mutation. Clinical Endocrinology 60 711-718.

Valyasevi RW, Erickson DZ, Harteneck DA, Dutton CM, Heufelder AE, Jyonouchi SC \& Bahn RS 1999 Differentiation of human orbital preadipocyte fibroblasts induces expression of functional thyrotropin receptor. Journal of Clinical Endocrinology and Metabolism 84 2557-2562.

Vassart G \& Dumont JE 1992 The thyrotropin receptor and the regulation of thyrocyte function and growth. Endocrine Reviews 13 596-611.

Virtanen KS, Lidell ME, Orava J, Heglind M, Westergren R, Nierni J, Taittonen M, Laine J, Savisto N-J, Enerback S et al. 2009 Functional brown adipose tissue in healthy adults. New England Journal of Medicine $3601518-1525$.

Vlaeminck-Guillem V, Ho SC, Rodien P, Vassart G \& Costagliola S 2002 Activation of the cAMP pathway by the TSH receptor involves switching of the ectodomain from a tethered inverse agonist to an agonist. Molecular Endocrinology 16 736-746.

Williams GR 2009 Does serum TSH level have thyroid hormone independent effects on bone turnover? Nature Reviews. Endocrinology 5 10-11.

Winand RJ \& Kohn LD 1972 The binding of $\left[{ }^{3} \mathrm{H}\right]$ thyrotropin and an ${ }^{3} \mathrm{H}$-labeled exophthalmogenic factor by plasma membranes of retro-orbital tissue. PNAS 69 1711-1715.

Zaballos MA, Garcia B \& Santisteban P 2008 G $\beta \gamma$ dimers released in response to thyrotropin activate phosphoinositide 3-kinase and regulate gene expression in thyroid cells. Molecular Endocrinology 22 1183-1199.

Zhang L, Baker G, Janus D, Paddon C, Fuhrer D \& Ludgate M 2006 Biological effects of thyrotropin receptor activation on human orbital preadipocytes. Investigative Ophthalmology \& Visual Science 47 5197-5203.

Zhang L, Paddon C, Lewis MD, Grennan-Jones F \& Ludgate M 2009 Gs $\alpha$ signalling suppresses PPAR $\gamma 2$ generation and inhibits 3T3L1 adipogenesis. Journal of Endocrinology 202 207-215.

Received in final form 28 August 2009

Accepted 16 September 2009

Made available online as an Accepted Preprint

16 September 2009 